\title{
Multiple use of waste catalysts with and without regeneration for waste polymer cracking
}

\begin{abstract}
Waste plastics contain a substantial number of valuable chemicals. The wastes from postconsumer as well as from industrial production can be recycled to valuable chemical feedstock, which can be used in refineries and/or petrochemical industries. This chemical recycling process is an ideal approach in recycling the waste for a better environment. Polymer cracking using a laboratory fluidised bed reactor concentrated on the used highly contaminated catalyst, E-Cat 2. Even though E-Cat 2 had low activity due to fewer acid sites, the products yielded were similar with amorphous ASA and were far better than thermal cracking. The high levels of heavy metals, namely nickel and vanadium, deposited during their lifetime as an FCC catalyst, did not greatly affect on the catalyst activity. It was also shown that E-Cat 2 could be used with and without regeneration. Although there was more deactivation when there was no regeneration step, the yield of gases (C2ï C7) remained fairly constant. For the first time, these results indicate that ñwasteò FCC catalyst (E-Cat) is a good candidate for future feedstock recycling of polymer waste. The major benefits of using E-Cat are a low market price, the ability to tolerate reuse and regeneration capacity.
\end{abstract}

Keyword: Recycling; Refuse disposal; Polymer wastes 